\title{
Estudo comparativo do cálculo analítico da ruptura de vigas de concreto armado simuladas através do Método de Elementos Finitos
}

\section{Comparative study of analytical calculation of breaking simulated reinforced concrete beams through finite elements method}

Gustavo Ricardo de Marco $^{1}$, Patrick de Oliveira Batista da Costa ${ }^{2 *}$, Gustavo de Miranda Saleme Gidrão ${ }^{3}$

\section{RESUMO}

A segurança das estruturas de concreto armado é garantida pelo correto dimensionamento às solicitações normais no estado-limite último. Os domínios de deformação propostos pela ABNT NBR 6118 de 2014 determinam as bases para o cálculo analítico de estruturas de concreto armado na ruptura, assumindo hipóteses básicas para simplificar a situação real. Por outro lado, o Método de Elementos Finitos auxilia na resolução de problemas complexos de meio contínuo por meio da divisão em elementos menores. Diante disso, buscou-se, neste estudo, desenvolver modelos numéricos que pudessem comprovar a precisão do cálculo analítico por meio de simulações de vigas de concreto armado no programa computacional Abaqus®. São apresentados o desenvolvimento das equações para um modelo de cálculo analítico, bem como o desenvolvimento do modelo numérico, cujos resultados foram objeto de análise comparativa do modo de falha. O modelo analítico se mostrou concordante com o modelo numérico; o primeiro por meio de dados quantitativos e, o segundo, por resultados gráficos, acabando por prever, de forma correta, o modo de ruptura de cada viga.

Palavras-chave: Elementos finitos; Concrete damage plasticity; Abaqus.

\begin{abstract}
The safety of reinforced concrete structures is guaranteed by the correct design to normal stresses in ultimate limit state. The deformation domains proposed by ABNT NBR 6118:2014 determine the bases for breaking reinforced concrete structures analytical calculation, assuming basic assumptions to simplify the real situation. The Finite Elements Analysis, however, assists in the resolution of complex continuum media problems by dividing them into smaller elements. In view of this, the present study sought to develop numerical models that could prove the precision of the analytical calculation through simulations of reinforced concrete beams in the computer program Abaqus ${ }^{\circledR}$. The development of the analytical model equations is presented, as well as the development of the numerical model, the results of which were object for comparative analysis of the failure mode. The analytical model proved to be in agreement with the numerical model; the first be means of quantitative data and, the second, by graphical results, ending up predicting, in a correct way, each beam failure mode.
\end{abstract}

Keywords: Finite elements; Concrete damage plasticity; Abaqus.

\footnotetext{
${ }^{1}$ FHO - Fundação Hermínio Ometto - Uniararas.

${ }^{2}$ UFRGS - Universidade Federal do Rio Grande do Sul.

*E-mail: patrick.costa@ufgrs.br

${ }^{3}$ UTFPR - Universidade Tecnológica Federal do Paraná.
} 


\section{INTRODUÇÃO}

A estabilidade das estruturas de concreto armado é assegurada quando seu projeto se fundamenta não apenas no atendimento das condições construtivas de detalhamento, controle de materiais e direção de execução da edificação, em concordância às Normas Brasileiras 6118, 12655 e 14931 (ABNT, 2014, 2015, 2004), respectivamente. Mas, sobretudo, a verificação do estado-limite último (ELU) de perda de equilíbrio como corpo rígido, segundo Carvalho e Figueiredo Filho, deve atender à condição que determina que o valor de cálculo dos esforços solicitantes deve ser menor ou igual ao valor de cálculo dos esforços resistentes (2014).

Os elementos lineares, mais especificamente as vigas de concreto armado, estão sujeitas a vários modos de ruptura. O cálculo desses elementos aplicando a resistência última dos materiais componentes representa o método analítico atualmente factível para o dimensionamento de peças integrantes das estruturas.

Paralelamente a isso, o Método de Elementos Finitos (MEF) é uma ferramenta de cálculo numérico capaz de resolver problemas de meio contínuo por meio da discretização, ou seja, subdividindo-o em elementos menores. As primeiras pesquisas e publicações sobre o assunto datam por volta de 1960. No entanto, com o advento do computador digital, o MEF se difundiu, principalmente na engenharia, na resolução de problemas físicos mais complexos. Os elementos finitos que discretizam uma dada estrutura ou componente estrutural, ligam-se entre si pelos chamados nós, formando uma malha pela qual se calcula o comportamento de cada elemento individual por meio de modelos matemáticos regidos por equações diferenciais para se obter o resultado da peça como um todo. As equações derivadas do MEF são resolvidas de forma computacional e convergem, à medida que se refina a malha do modelo, para a solução física mais aproximada (BATHE, 2006).

Ante o exposto, o estudo em tela se propôs a realizar análises comparativas da simulação de vigas de concreto armado pelo Método de Elementos Finitos com o desenvolvimento das equações analíticas, seguindo as prescrições da NBR 6118 (ABNT, 2014) para dimensionamento de vigas de concreto armado, utilizando o modo de falha do material com o propósito de fazer uma avaliação qualitativa da precisão do método analítico através da validação pelo modelo numérico. 


\section{ESTUDO DE CASO}

O presente estudo teve como escopo investigar a precisão do método analítico de dimensionamento a esforços normais por meio da validação por um modelo numérico.

A intenção foi estudar o modo de ruptura de vigas, uma vez que o dimensionamento é feito no estado-limite último. Para esse fim, a análise foi feita em duas partes. Primeiro, foram desenvolvidas equações capazes de calcular a força máxima que um modelo de viga suporta antes da ruptura e prever de qual forma a falha ocorreria. Após, a mesma viga foi simulada de forma computacional pelo Método de Elementos Finitos a fim de ratificar os resultados obtidos pelo método analítico através de uma avaliação comparativa de ambos os métodos.

A fim de obter um estudo completo abrangendo mais de uma situação de ruína e diferentes configurações de armadura e altura, foram idealizados sete modelos de vigas retangulares bi apoiadas, conforme descreve a tabela a seguir. $\mathrm{O}$ vão de todos os modelos é de $300 \mathrm{~cm}$.

Quadro 1 - Características geométricas e materiais dos modelos de viga

\begin{tabular}{|c|c|c|c|c|}
\hline \multirow{2}{*}{ Modelo } & \multicolumn{2}{|c|}{ Seção transversal } & \multirow{2}{*}{$\begin{array}{c}\mathrm{c}_{\mathrm{nom}} \\
(\mathrm{mm})\end{array}$} & \multirow{2}{*}{$\begin{array}{c}\mathrm{f}_{\mathrm{ck}} \\
(\mathrm{MPa})\end{array}$} \\
\hline & $\mathrm{b}(\mathrm{cm})$ & $\mathrm{h}(\mathrm{cm})$ & & \\
\hline 1 & 15 & 30 & 30 & 30 \\
\hline 2 & 15 & 35 & 30 & 30 \\
\hline 3 & 15 & 40 & 30 & 30 \\
\hline 4 & 15 & 45 & 30 & 30 \\
\hline 5 & 15 & 50 & 30 & 30 \\
\hline 6 & 15 & 55 & 30 & 30 \\
\hline 7 & 15 & 60 & 30 & 30 \\
\hline
\end{tabular}

Fonte: Os Autores (2021)

\section{Modelo analítico}

A formulação de um modelo de cálculo para a ruptura de vigas teve como finalidade obter uma relação de igualdade que permitisse prever a força concentrada, representativa do carregamento máximo, que os modelos de vigas suportam antes de romper. Como o dimensionamento, segundo a NBR 6118 (ABNT, 2014), pode ser feito considerando os esforços normais separadamente, desenvolveu-se uma equação para calcular a força responsável pela flexão e uma que descreve a força cortante máxima a partir do dimensionamento. 


\section{Força máxima na flexão}

Supondo uma viga solicitada a uma força desconhecida Fmáx e considerando os esforços internos de tração e compressão, temos o esquema estático definido a seguir.

Figura 1 - Esquema estático para elaboração do modelo analítico
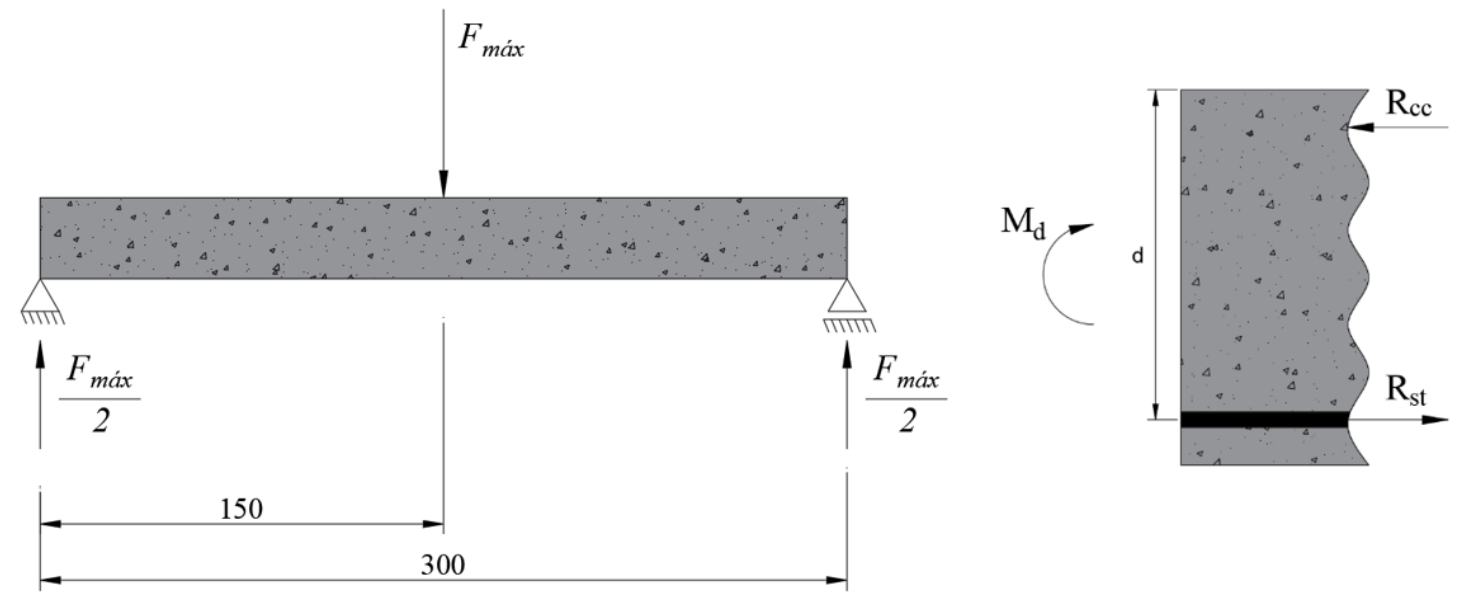

Fonte: Os Autores (2021)

É importante ressaltar que o propósito é encontrar o valor máximo teórico do esforço ao qual a viga resiste. Diante disso, são desconsiderados os coeficientes de ponderação minoradores de resistência dos materiais.

Tabela 1 - Áreas de armadura longitudinal dos modelos de viga

\begin{tabular}{|c|c|c|c|c|c|c|c|c|}
\hline \multirow{3}{*}{ Modelo } & \multicolumn{3}{|c|}{ Seção transversal } & \multirow{2}{*}{$\begin{array}{c}\text { Dimensionamento } \\
\text { prévio }\end{array}$} & \multirow{3}{*}{\multicolumn{2}{|c|}{$\begin{array}{l}\text { Armadura } \\
\text { atribuída }\end{array}$}} & \multirow{3}{*}{$\begin{array}{l}\text { Ast } \\
\left(\mathrm{cm}^{2}\right)\end{array}$} & \multirow{3}{*}{$\begin{array}{c}\text { Variação* } \\
(\%)\end{array}$} \\
\hline & $\mathrm{b}$ & $\mathrm{h}$ & d & & & & & \\
\hline & $(\mathrm{cm})$ & $(\mathrm{cm})$ & $(\mathrm{cm})$ & Ast $\left(\mathrm{cm}^{2}\right)$ & & & & \\
\hline 1 & 15 & 30 & 25,6 & 4,06 & $2 \varphi$ & $\varphi \quad 16,0 \mathrm{~mm}$ & 4,02 & $-0,88 \%$ \\
\hline 2 & 15 & 35 & 30,7 & 4,88 & $4 \varphi$ & $\varphi 12,5 \mathrm{~mm}$ & 4,91 & $0,63 \%$ \\
\hline 3 & 15 & 40 & 35,6 & 5,64 & $3 \varphi$ & $\varphi 16,0 \mathrm{~mm}$ & 6,03 & $6,88 \%$ \\
\hline 4 & 15 & 45 & 40,6 & 6,44 & $3 \varphi$ & $\varphi 16,0 \mathrm{~mm}$ & 6,03 & $-6,30 \%$ \\
\hline 5 & 15 & 50 & 45,7 & 7,26 & $6 \varphi$ & $\varphi 12,5 \mathrm{~mm}$ & 7,36 & $1,45 \%$ \\
\hline 6 & 15 & 55 & 50,6 & 8,02 & $4 \varphi$ & $\varphi 16,0 \mathrm{~mm}$ & 8,04 & $0,23 \%$ \\
\hline 7 & 15 & 60 & 55,6 & 8,82 & $4 \varphi$ & $\varphi 16,0 \mathrm{~mm}$ & 8,04 & $-8,79 \%$ \\
\hline
\end{tabular}

Para a armadura transversal, supôs-se barras de $6,3 \mathrm{~mm}$ de diâmetro a cada 15 centímetros para estribos retangulares de dois ramos em todos os modelos.

Fonte: Os Autores (2021) 


\section{Modelo numérico}

A construção do modelo numérico foi feita no Abaqus/CAE, um software da companhia francesa Dassault Systèmes que possibilita análises pelo Método de Elementos Finitos (MEF) por meio de uma interface simples envolvendo recursos de criação, submissão, monitoramento e avaliação de resultados. Esse ambiente, subdividido em módulos, começa na modelagem com definições de geometria, propriedades materiais, condições de contorno e geração de malha. Esses dados geram um arquivo de entrada que é calculado pelo módulo de análise e pode ser monitorado pelo usuário para, ao final, gerar os dados de saída para visualização e avaliação dos resultados que serão objeto de comparação ao final do estudo (ABAQUS, 2014).

\section{Geometria}

Foram gerados 7 modelos de viga de concreto com as características geométricas em concordância ao quadro 1. As armaduras foram delineadas de acordo com o disposto na tabela 1. O desenho das barras longitudinais incluiu um comprimento de ancoragem calculado por " $8 \varphi$ ", ou seja, $10 \mathrm{~cm}$ para barras de $12,5 \mathrm{~mm}$ e $13 \mathrm{~cm}$ para barras de 16,0 mm para que não houvesse falha na ancoragem.

As vigas em concreto foram modeladas em elemento sólido de 3 dimensões com 8 nós e integração reduzida, ou C3D8R (DHONDT, 2014). Já as armaduras, tanto longitudinal quanto transversal, foram modeladas em elemento de treliça de 3 dimensões com deslocamento linear de 2 nós, ou T3D2 (ABAQUS, 2014). A malha gerada para os dois elementos foi com tamanho global de $5 \mathrm{~cm}$.

Figura 2 - Elemento C3D8R (a) e T3D2 (b)

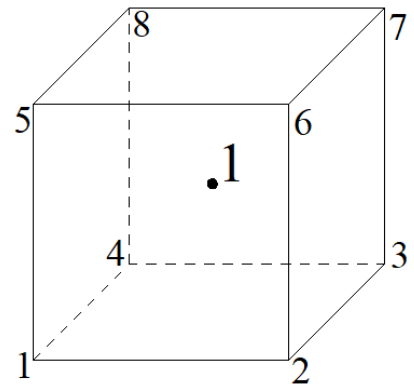

a)

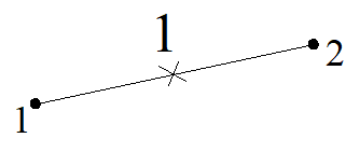

b)

Fonte: Os Autores (2021) 


\section{Propriedades materiais}

Das propriedades elásticas do concreto, o módulo de elasticidade inicial resultou, aproximadamente, para fck de $30 \mathrm{MPa}$, em 30672,46 MPa. O coeficiente de Poisson ( $v$ ) foi definido em 0,2 (ABNT, 2014).

A não linearidade física do concreto foi definida empregando o modelo constitutivo embutido no Abaqus de dano plástico progressivo do concreto chamado concrete damaged plasticity. O modelo considera a Teoria da Plasticidade com deformações plásticas de tração e compressão equivalentes aos mecanismos de degradação descritos pela mecânica do dano a fim de representar o comportamento inelástico do concreto através da perda da rigidez quando este atinge a resistência máxima (ABAQUS, 2014). Os parâmetros definidos pelo concrete damaged plasticity estão dispostos na tabela 2 .

Tabela 2 - Propriedades plásticas do concreto

\begin{tabular}{cccccc}
\hline Material & Ângulo de dilatação $(\psi)$ & Excentricidade $(e)$ & $f_{b 0} / f_{c 0}$ & $k$ & Viscosidade $(v)$ \\
\hline C30 & $45^{\circ}$ & 0.1 & 1.05 & 0.667 & 0.0001 \\
\hline
\end{tabular}

Fonte: Os Autores (2021)

Para a inserção dos valores de tensão e deformação plástica, bem como o dano no concreto tanto à compressão como à tração, foram aplicadas as relações empíricas de Carreira e Chu (1986), que definem o comportamento do concreto através da associação do ponto de tensão máxima (fc'/ft') e sua correspondente deformação ( $\left.\varepsilon c^{\prime} / \varepsilon t^{\prime}\right)$ e o parâmetro $(\beta)$ que depende da forma do diagrama de tensão e deformação $(1985,1986)$.

Para as armaduras foi adotado o aço CA-50 com o comportamento de tensão e deformação definido pelo modelo elasto-plástico perfeito, já ilustrado previamente pela figura 2, com tensão de escoamento (fy) de $500 \mathrm{MPa}$ e deformação máxima ( $\varepsilon u$ ) de $10 \%$. Para o módulo de elasticidade (Es), as normas internacionais admitem, quando não se dispõe de informações precisas ou ensaios mecânicos, que a grandeza seja definida por valores em torno de 200 e 210 GPa (ABNT, 2014; ACI, 2019; CEB, 1993; CEN, 2014). Para este estudo, sendo mais conservador, empregou-se o módulo de elasticidade do aço com $200 \mathrm{GPa}$. O coeficiente de Poisson (v) foi definido em 0,35 (ABNT, 2014).

\section{Método de análise}

Os tipos de análises oferecidas pelo Abaqus se baseiam na divisão do problema em steps (fases). A simulação de cada modelo utilizou-se de apenas um step, com a 
mudança gradativa da magnitude do deslocamento aplicado até a ruptura, configurando uma análise estática não linear física (ABAQUS, 2014). A solidarização do concreto e do aço foi garantida pela restrição dos graus de liberdade dos nós dos elementos de barra através do embutimento destas no concreto (embedded region), promovendo a aderência perfeita entre eles (ABAQUS, 2014).

No meio do vão da fibra superior foi aplicada a condição de contorno (boundary condition) que aplica deslocamento vertical para baixo (eixo y). A magnitude definida no programa teve o intuito de deformar o modelo até atingir a tensão de ruptura; sendo assim, o conhecimento de seu valor absoluto é trivial, desde que seja garantido que houve a ruína dos modelos. Na fibra inferior, com espaçamento de $10 \mathrm{~cm}$ das laterais, aplicou-se as condições de contorno restringindo o deslocamento nos eixos x e y para simular o apoio fixo e restringindo o deslocamento em y para simular o apoio móvel.

\section{RESULTADOS E DISCUSSÃO}

\section{Avaliação do modelo analítico}

Antes de avaliar o modo de falha de cada modelo de viga, foi verificada a possibilidade de ruína das diagonais comprimidas do concreto. A tabela a seguir mostra a parcela resistente do concreto $(\mathrm{Vc})$, a parcela resistente da armadura transversal (Vsw), a força máxima cortante resistida pelo modelo (Vmáx) e o esforço resistente à ruína das diagonais comprimidas (VRd,2).

Tabela 3 - Verificação à ruptura das bielas de compressão

\begin{tabular}{cccccc}
\hline Modelo & $\begin{array}{c}\mathrm{A}_{\mathrm{sw}} / \mathrm{s} \\
\left(\mathrm{cm}^{2} / \mathrm{cm}\right)\end{array}$ & $\begin{array}{c}\mathrm{V}_{\mathrm{c}} \\
(\mathrm{kN})\end{array}$ & $\begin{array}{c}\mathrm{V}_{\mathrm{sw}} \\
(\mathrm{kN})\end{array}$ & $\begin{array}{c}\mathrm{V}_{\text {máx }} \\
(\mathrm{kN})\end{array}$ & $\begin{array}{c}\mathrm{V}_{\mathrm{Rd}, 2} \\
(\mathrm{kN})\end{array}$ \\
\hline 1 & 0,0416 & 46,7 & 47,8 & 94,5 & 273,4 \\
2 & 0,0416 & 56,1 & 57,5 & 113,6 & 328,7 \\
3 & 0,0416 & 64,9 & 66,5 & 131,4 & 380,3 \\
4 & 0,0416 & 74,0 & 75,9 & 149,9 & 433,8 \\
5 & 0,0416 & 83,5 & 85,6 & 169,0 & 489,1 \\
6 & 0,0416 & 92,3 & 94,6 & 186,9 & 540,7 \\
7 & 0,0416 & 101,4 & 103,9 & 205,3 & 594,2 \\
\hline
\end{tabular}

Fonte: Os Autores (2021)

Por meio da análise da Tabela 3 e da Figura 3, percebe-se que não haverá ruína das bielas de compressão, visto que, dada a configuração de armadura e seção transversal 
do concreto, as peças rompem por tração diagonal antes de atingir o limite de resistência das diagonais comprimidas.

Os valores encontrados encontram-se na Tabela $4 \mathrm{em}$ módulo, pois a força em questão tem seu sentido para baixo e, pela convenção de sinais, é negativa. Foi disposta na coluna adjacente a força cortante máxima. Pela comparação dos dois parâmetros, construiu-se a coluna de modo de falha, onde o menor esforço é atribuído à causa de ruptura.

Figura 3 - Gráfico comparativo entre os resultados de $V_{\text {máx }}$ e $V_{R d, 2}$

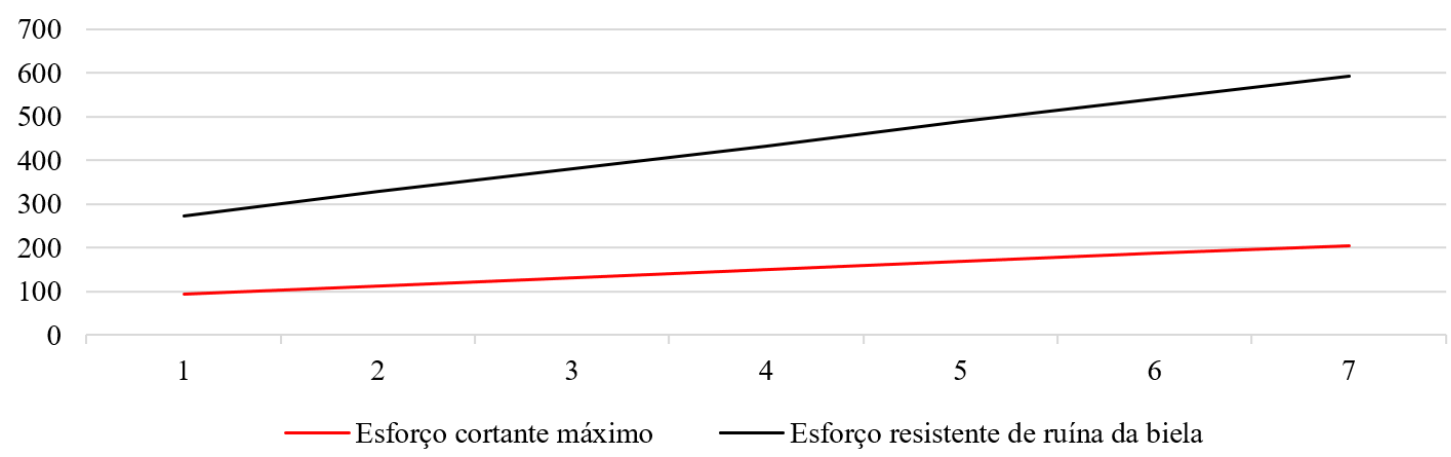

Fonte: Os Autores (2021)

Tabela 4 - Avaliação dos modos de falha pelo modelo analítico

\begin{tabular}{cccc}
\hline Modelo & $\begin{array}{c}\mathrm{F}_{\text {máx }} \\
(\mathrm{kN})\end{array}$ & $\begin{array}{c}\mathrm{V}_{\text {máx }} \\
(\mathrm{kN})\end{array}$ & $\begin{array}{c}\text { Modo de } \\
\text { falha }\end{array}$ \\
\hline 1 & 61,38 & 94,48 & Flexão \\
2 & 90,24 & 113,61 & Flexão \\
3 & 129,16 & 131,44 & Flexão \\
4 & 145,09 & 149,91 & Flexão \\
5 & 201,60 & 169,03 & Cisalhamento \\
6 & 243,09 & 186,86 & Cisalhamento \\
7 & 264,07 & 205,34 & Cisalhamento \\
\hline
\end{tabular}

Fonte: Os Autores (2021)

A Figura 4 ilustra os dados da tabela supra e, através dela, verifica-se que o rompimento da peça se dá por flexão quanto a força máxima no meio do vão é inferior em relação à força máxima cortante. De maneira análoga, quando a força máxima cortante for menor que a máxima do meio do vão, a falha ocorre por cisalhamento. 
Figura 4 - Gráfico comparativo de esforços máximos de flexão e cisalhamento

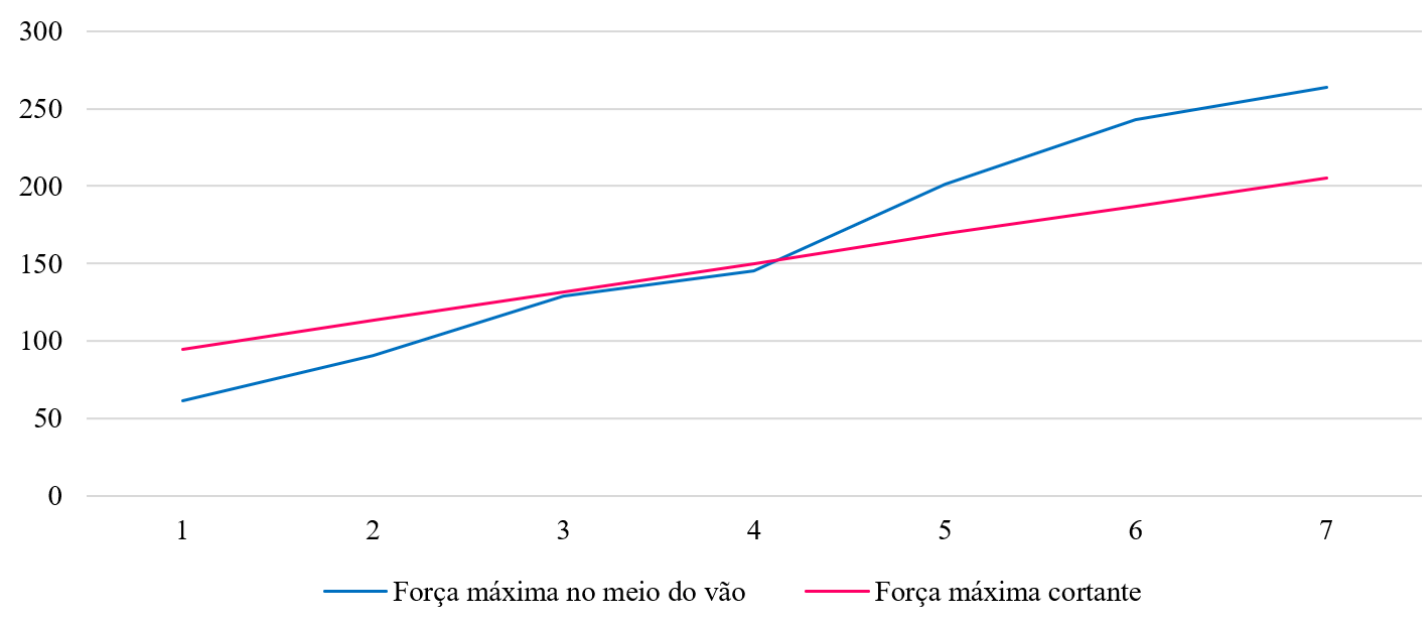

Fonte: Os Autores (2021)

\section{Avaliação do modelo numérico}

Concluída a simulação e resolução dos modelos, foi extraído do pósprocessamento do Abaqus os resultados gráficos da tensão de von Mises nas armaduras e do dano no concreto sob tração.

Através da tensão de von Mises que salienta a ruptura do material dúctil pelo escoamento, foi possível observar onde ocorreu a falha nas armaduras. Este parâmetro, associado ao dano de tração no concreto permitiu observar o comportamento conjunto dos materiais componentes do concreto armado e inferir uma análise qualitativa do modo de falha da peça.

Nas três primeiras simulações, as vigas atingiram a tensão de escoamento das armaduras inicialmente no meio do vão das barras longitudinais. $\mathrm{O}$ dano à tração do concreto demonstrou intensa deformação e ruptura plástica a partir da fibra inferior, características da fissuração vertical. Verificou-se, dessa forma, que os modelos 1,2 e 3 vieram à ruína antes por flexão. 
Figura 5 - Evolução da tensão de von Mises e do dano à tração no modelo $1(1 / 3)$

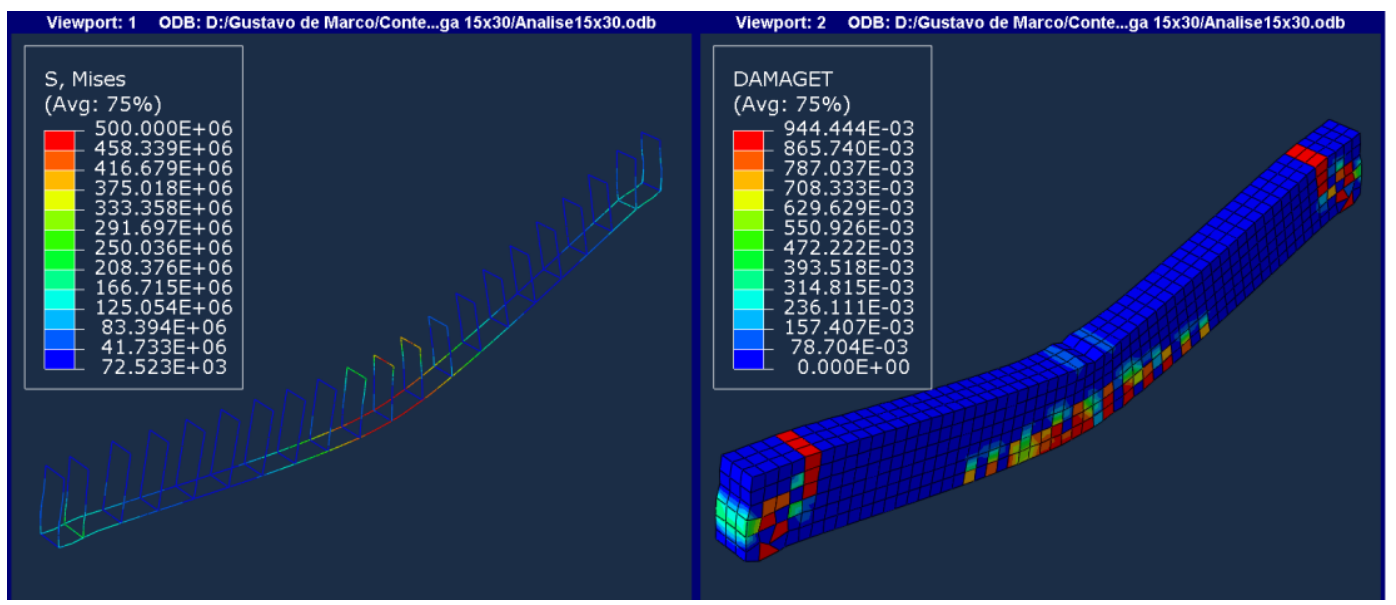

Fonte: Os Autores (2021)

Figura 6 - Evolução da tensão de von Mises e do dano à tração no modelo $1(2 / 3)$

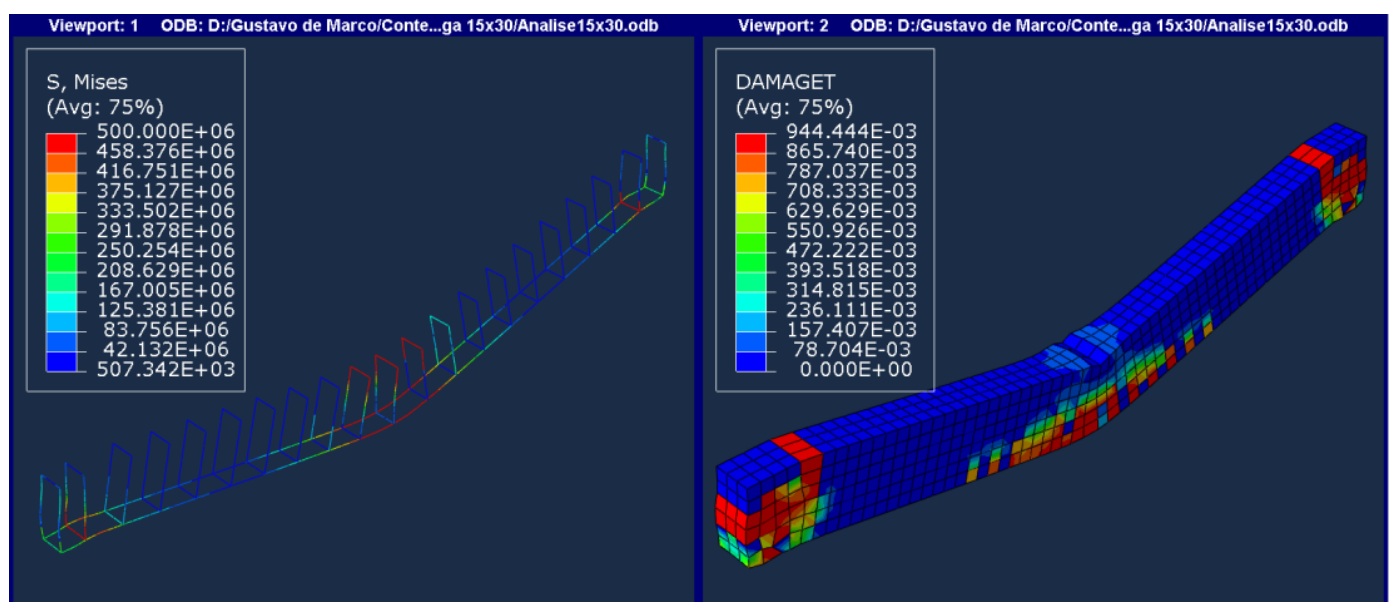

Fonte: Os Autores (2021)

Figura 7 - Evolução da tensão de von Mises e do dano à tração no modelo 1 (3/3)

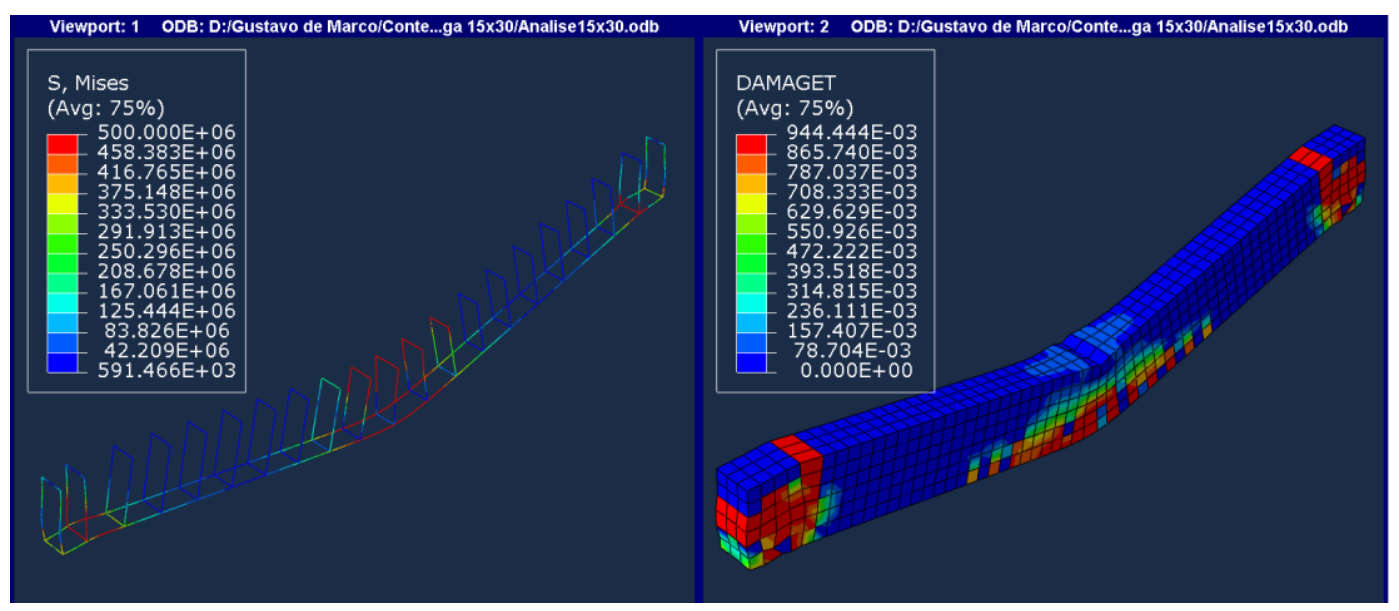

Fonte: Os Autores (2021) 
Figura 8 - Evolução da tensão de von Mises e do dano à tração no modelo 2 (1/3)

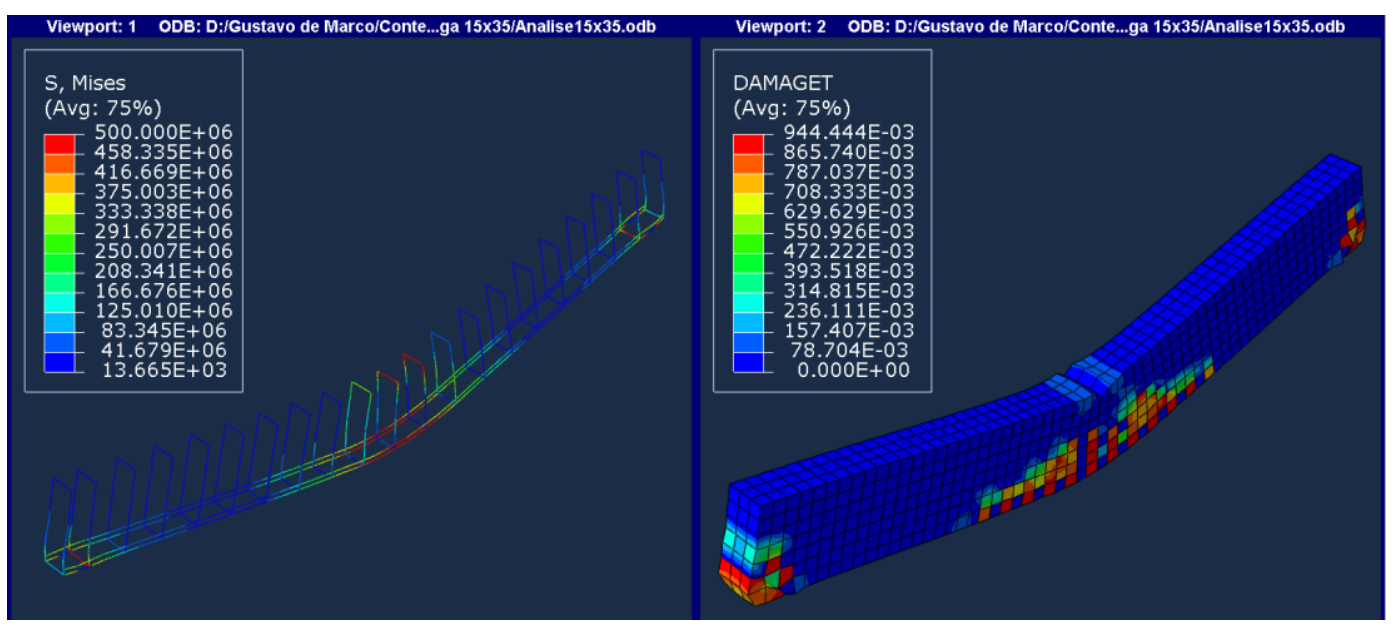

Fonte: Os Autores (2021)

Figura 9 - Evolução da tensão de von Mises e do dano à tração no modelo 2 (2/3)

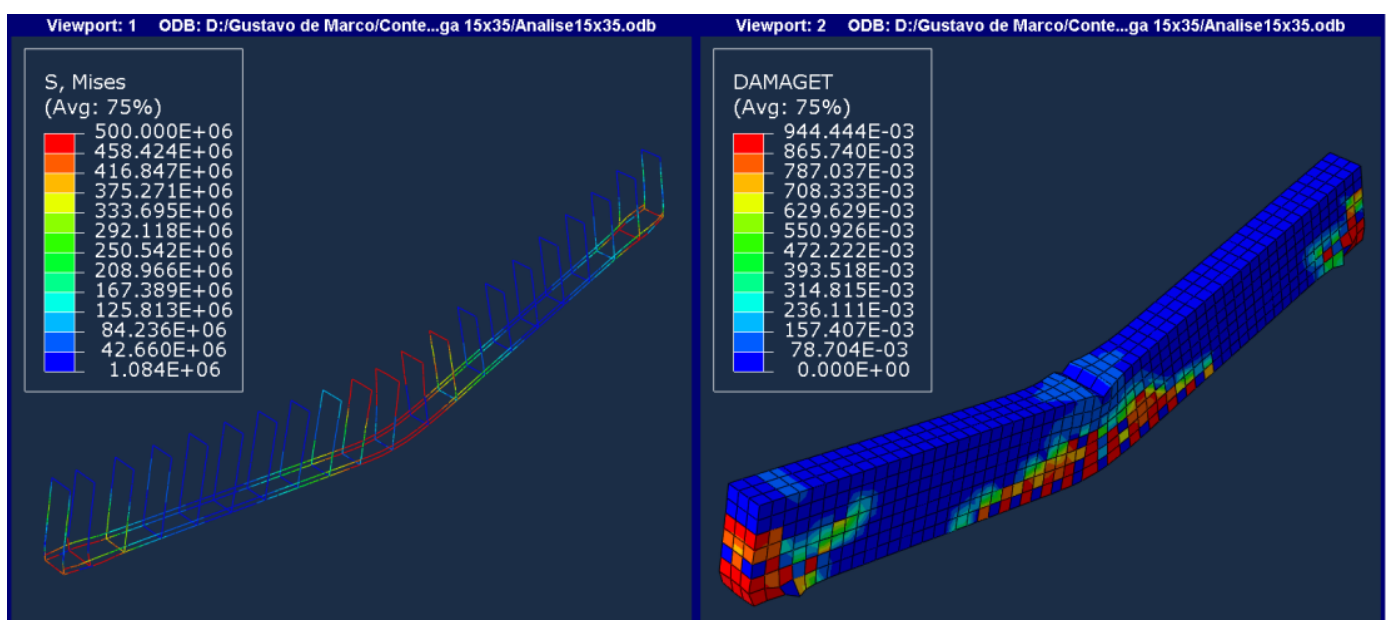

Fonte: Os Autores (2021)

Figura 10 - Evolução da tensão de von Mises e do dano à tração no modelo 2 (3/3)

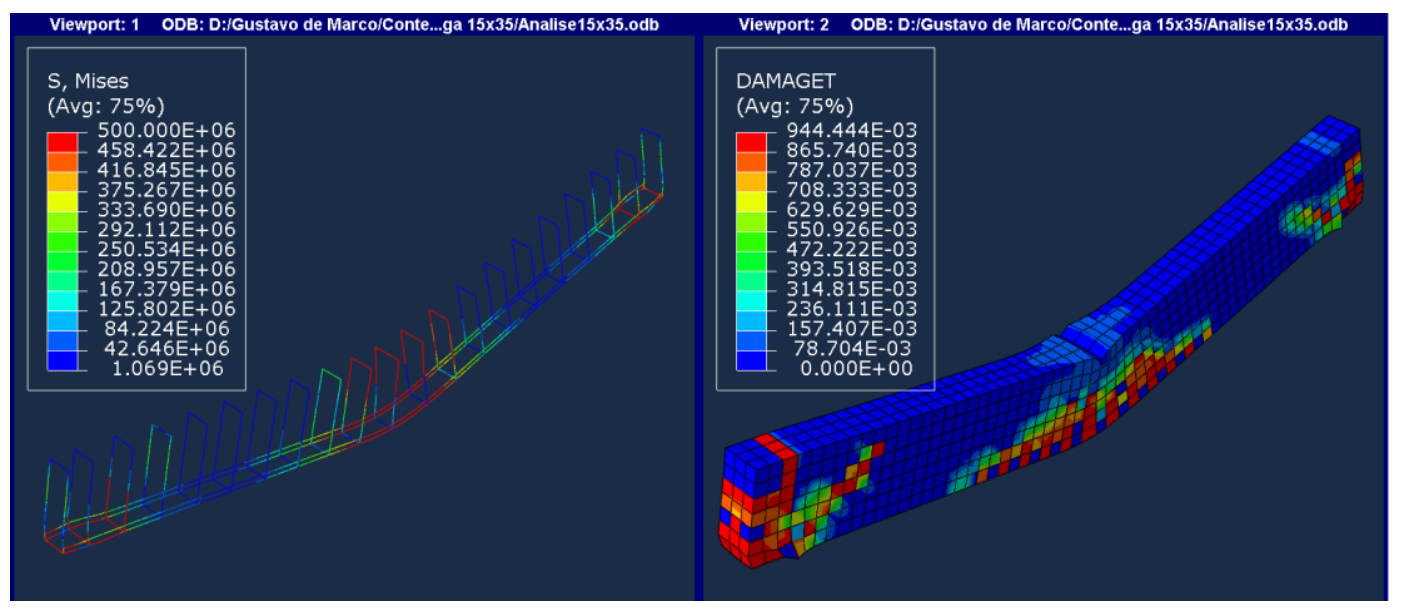

Fonte: Os Autores (2021) 
Figura 11 - Evolução da tensão de von Mises e do dano à tração no modelo 3 (1/3)

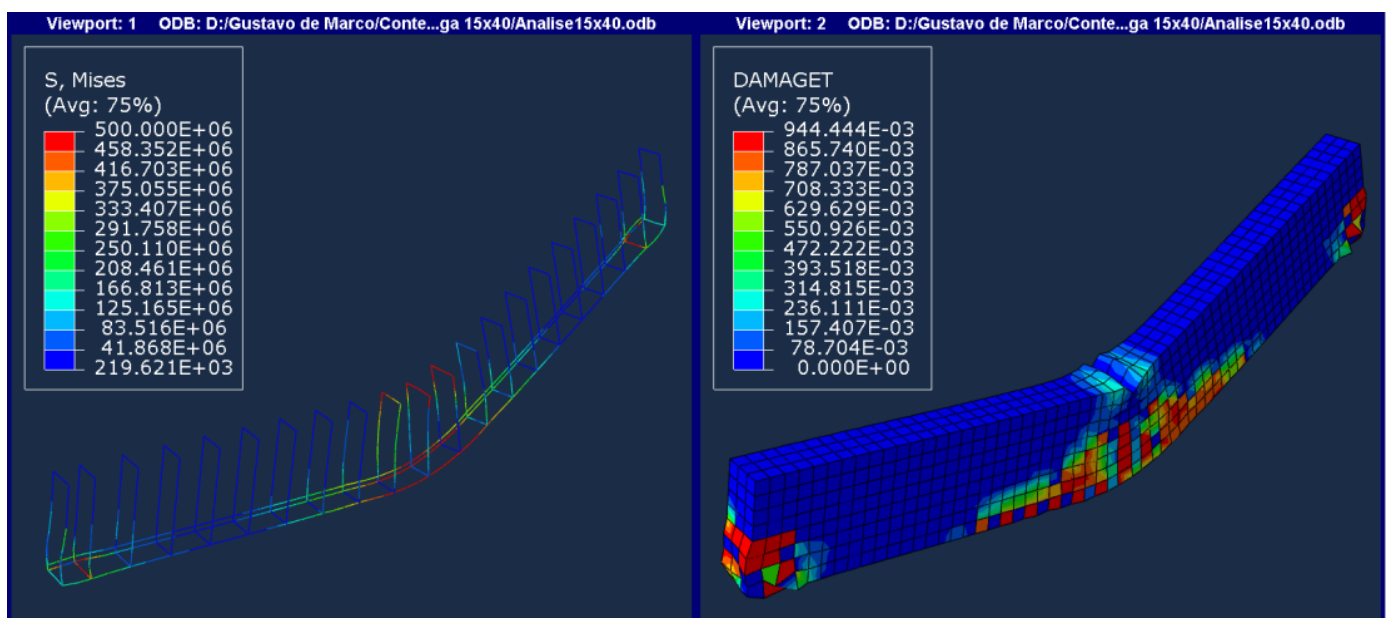

Fonte: Os Autores (2021)

Figura 12 - Evolução da tensão de von Mises e do dano à tração no modelo 3 (2/3)

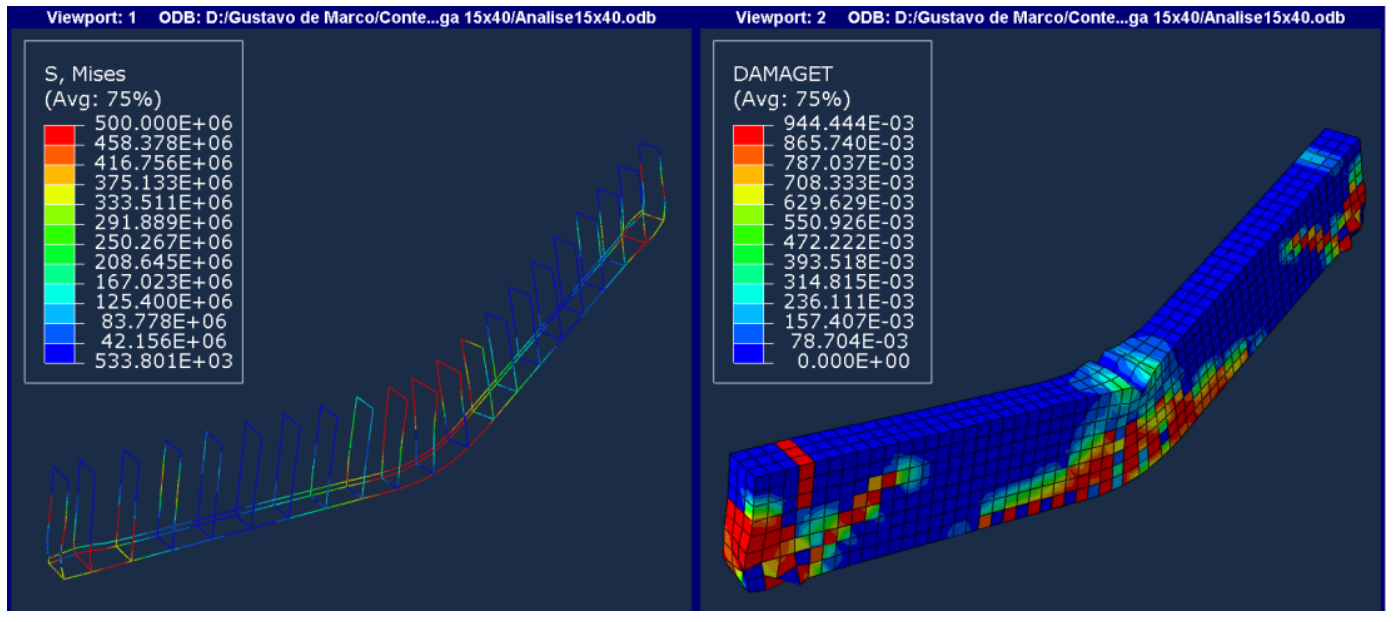

Fonte: Os Autores (2021)

Figura 13 - Evolução da tensão de von Mises e do dano à tração no modelo 3 (/3)

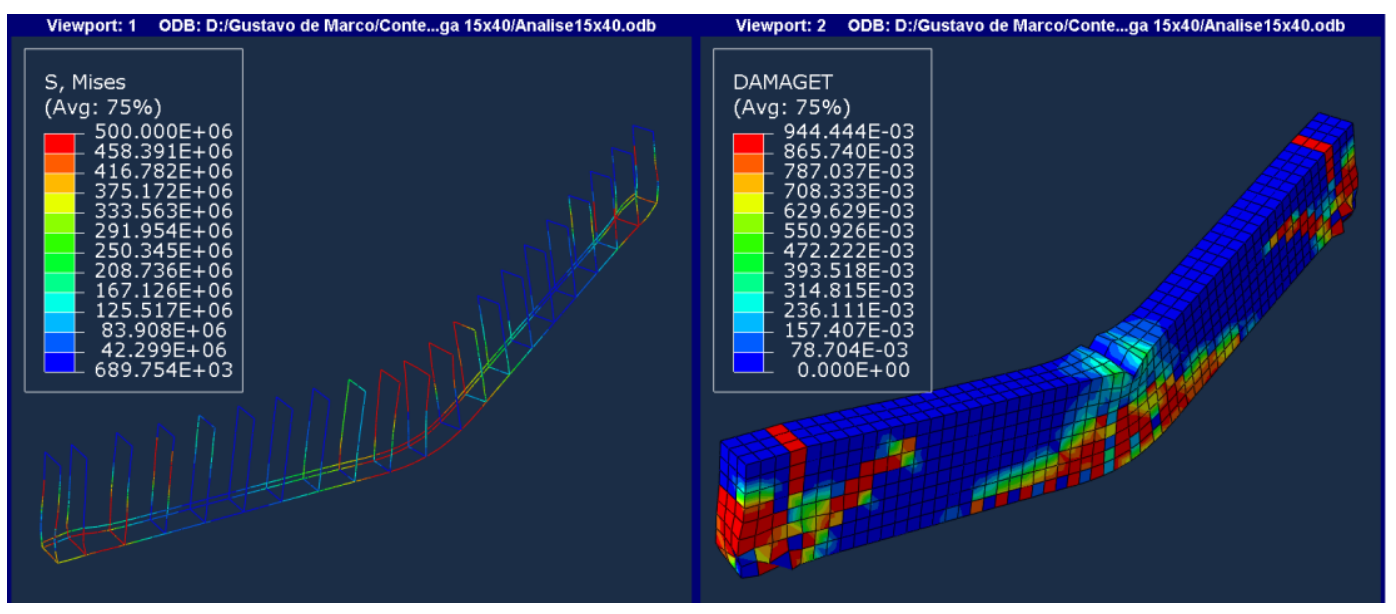

Fonte: Os Autores (2021) 
A partir do quarto modelo, começou a ser observado a manifestação do esforço cortante, principalmente próximo ao meio do vão. Apesar disso, a viga ainda rompe primeiro por flexão, pois apresenta uma influência mais significativa do que quando comparado ao esforço cisalhante.

Figura 14 - Evolução da tensão de von Mises e do dano à tração no modelo 4 (1/3)

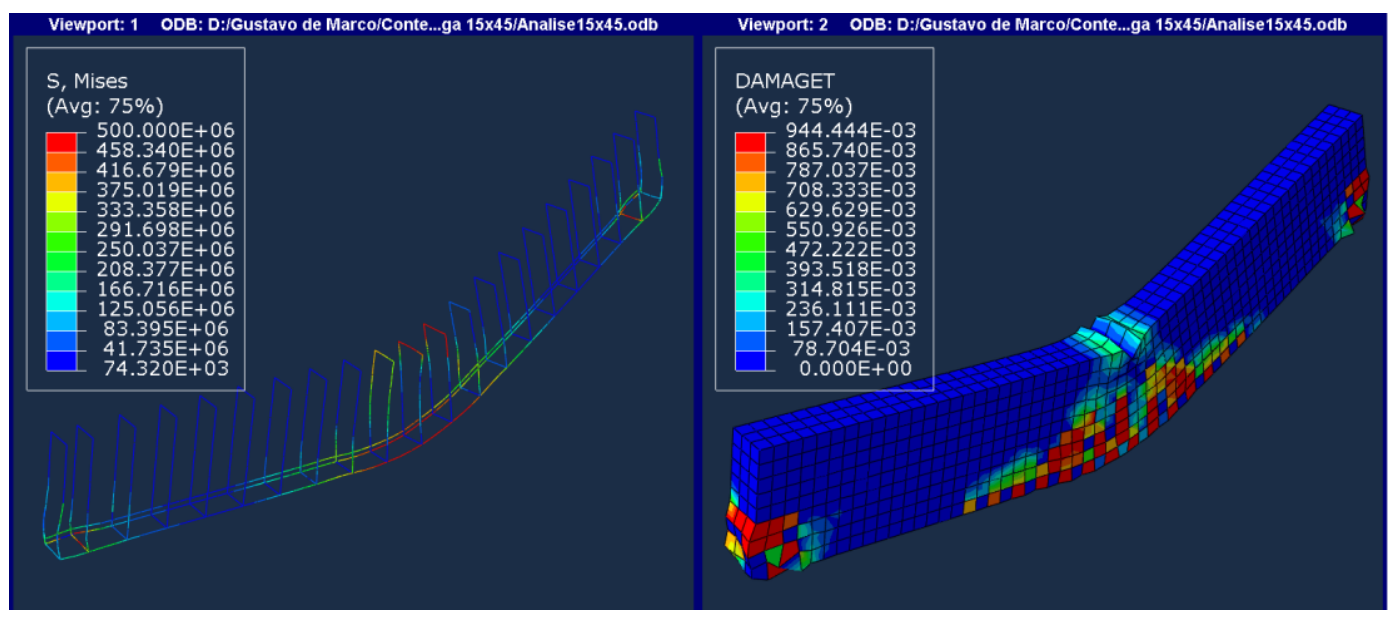

Fonte: Os Autores (2021)

Figura 15 - Evolução da tensão de von Mises e do dano à tração no modelo 4 (2/3)

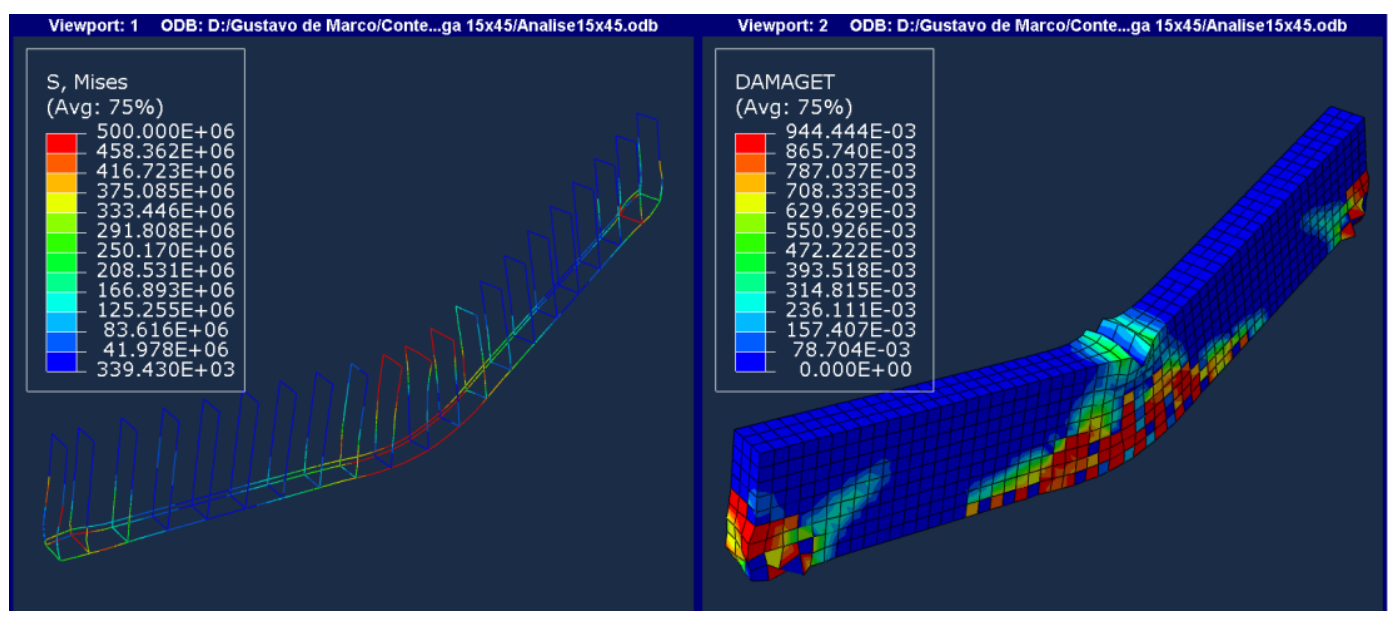

Fonte: Os Autores (2021) 
Figura 16 - Evolução da tensão de von Mises e do dano à tração no modelo 4 (3/3)

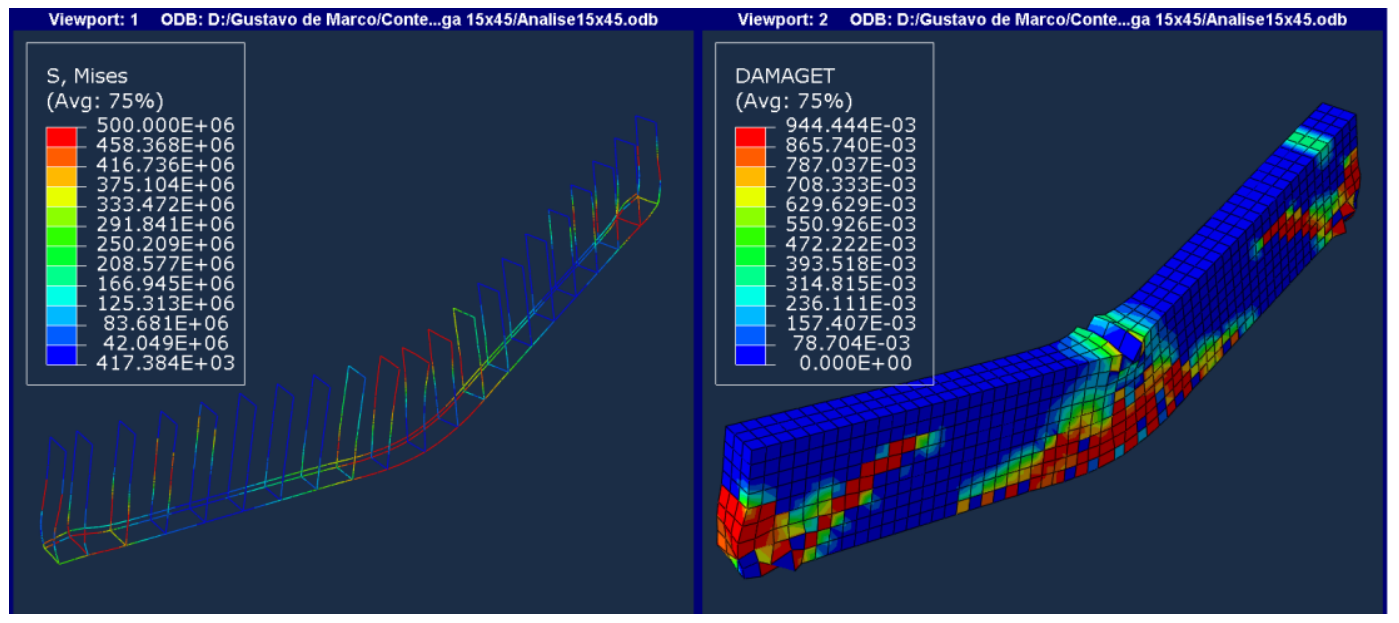

Fonte: Os Autores (2021)

O quinto modelo exigiu uma análise mais cuidadosa, pois foi a peça onde a ruína por flexão e por cisalhamento aconteceram quase ao mesmo tempo, ou seja, a transição entre o modo de falha começou a ser observada a partir desse modelo. Apesar de o esforço fletor se desenvolver primeiro, após a progressão das tensões internas da viga constatouse acentuado esforço cisalhante, com tração diagonal no concreto em direção ao meio do vão e escoamento das armaduras transversais no mesmo sentido, enquanto que as armaduras longitudinais não chegaram a romper em sua totalidade, induzindo ao juízo de que o modelo de viga rompeu por cisalhamento.

Figura 17 - Evolução da tensão de von Mises e do dano à tração no modelo 5 (1/3)

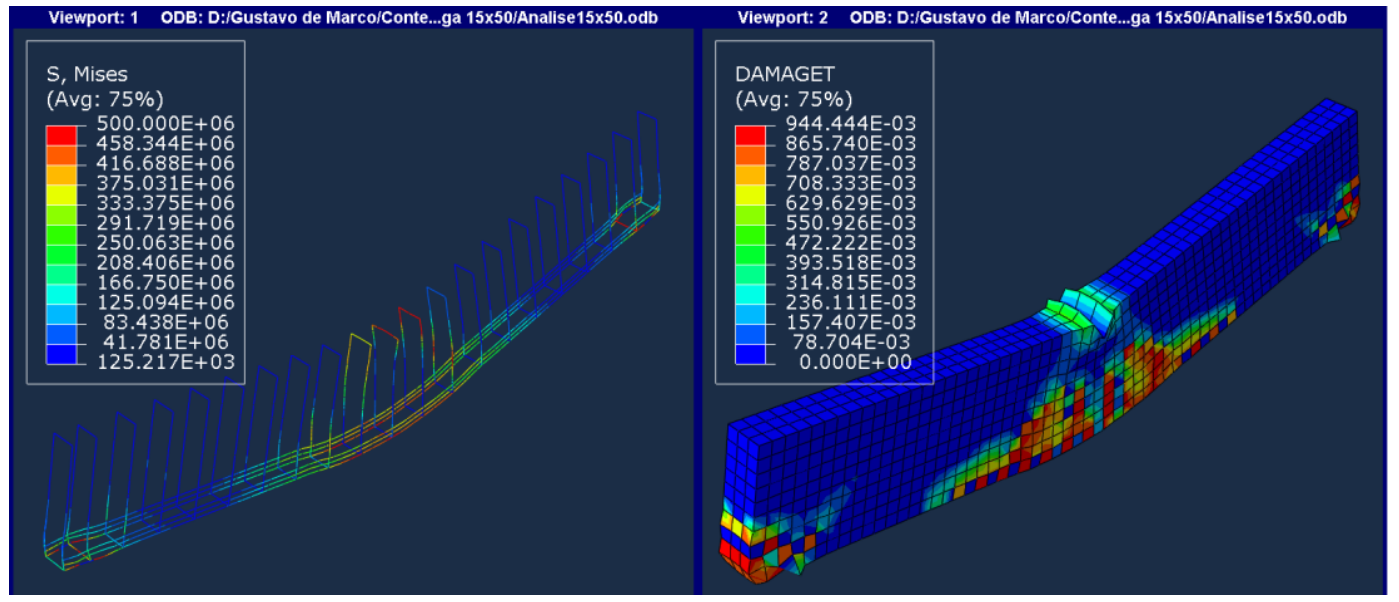

Fonte: Os Autores (2021) 
Figura 18 - Evolução da tensão de von Mises e do dano à tração no modelo 5 (2/3)

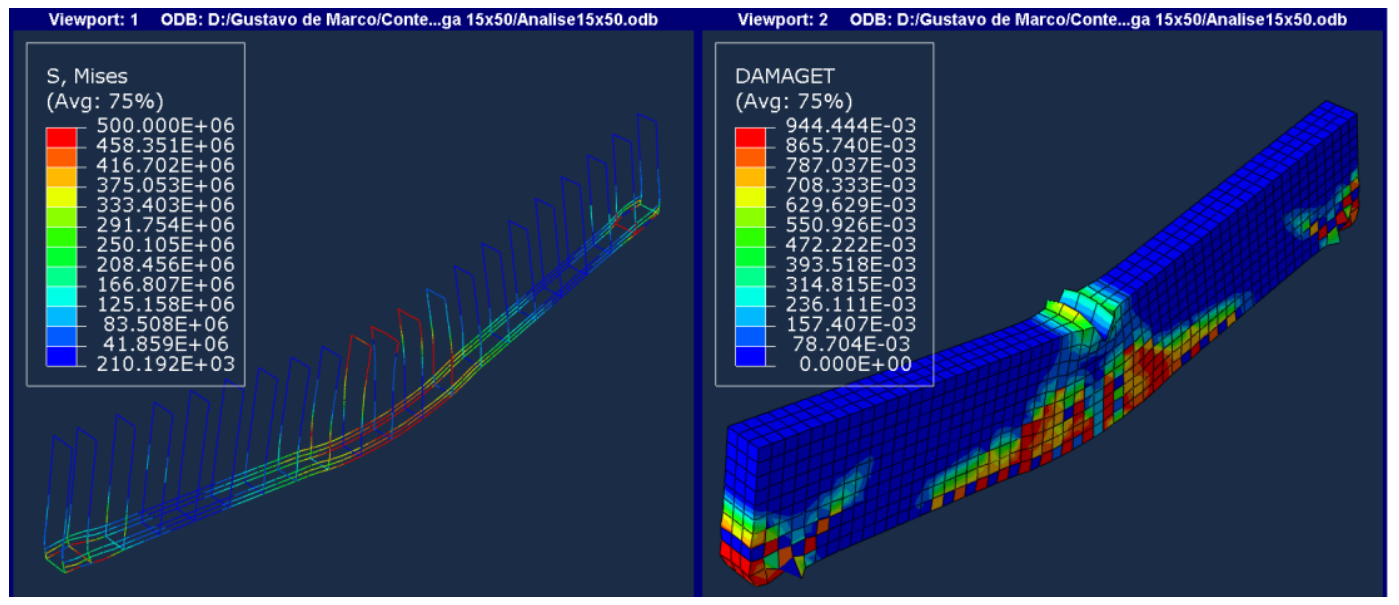

Fonte: Os Autores (2021)

Figura 19 - Evolução da tensão de von Mises e do dano à tração no modelo 5 (3/3)

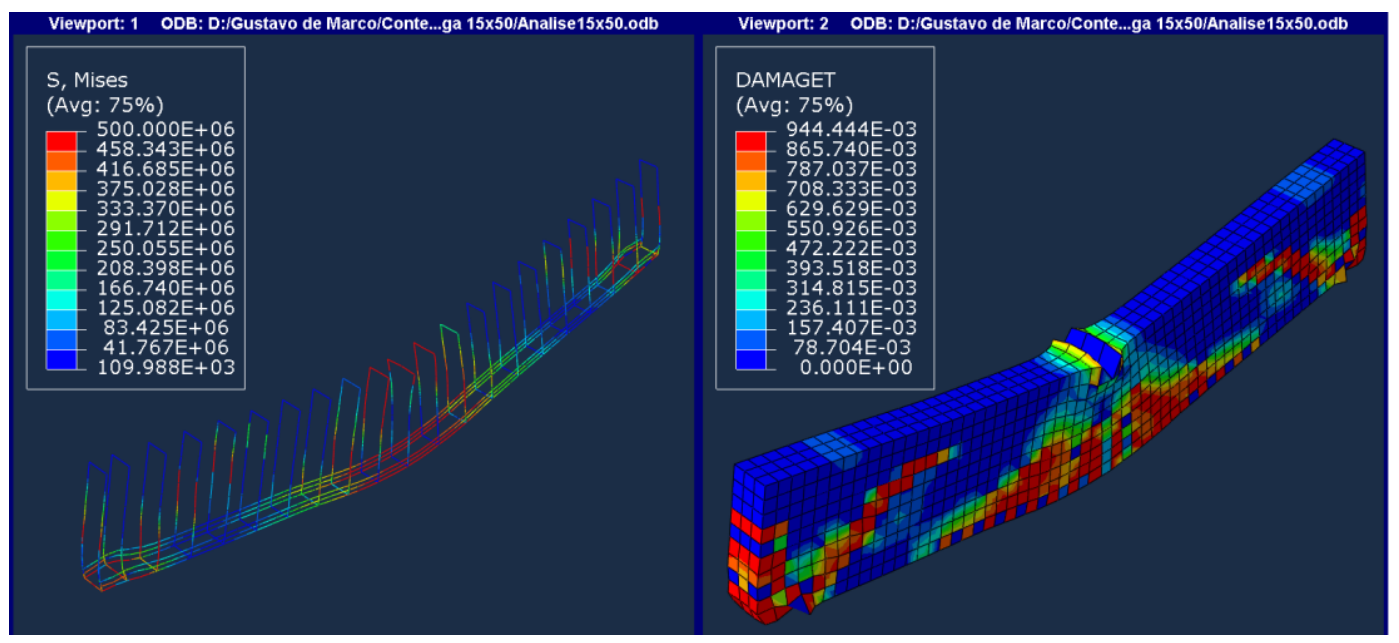

Fonte: Os Autores (2021)

Por fim, os modelos 6 e 7 romperam explicitamente por cisalhamento. Ambas as vigas mostraram dano diagonal do concreto tracionado na direção do banzo comprimido, desde os apoios, se desenvolvendo até o meio do vão. As armaduras transversais ultrapassaram a tensão de escoamento nesses pontos, ao passo que as armaduras longitudinais não chegam a atingir o escoamento em sua totalidade, qualificando a ruína decorrente do esforço cortante. 
Figura 20 - Evolução da tensão de von Mises e do dano à tração no modelo 6 (1/3)

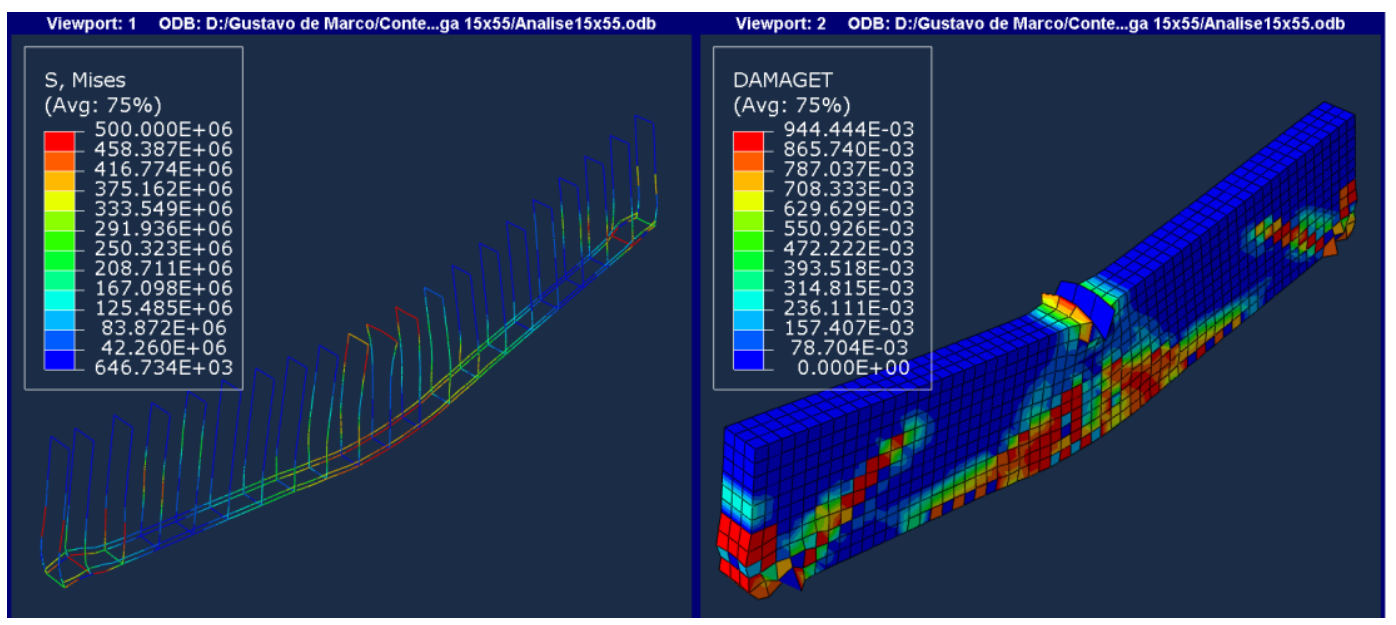

Fonte: Os Autores (2021)

Figura 21 - Evolução da tensão de von Mises e do dano à tração no modelo 6 (2/3)

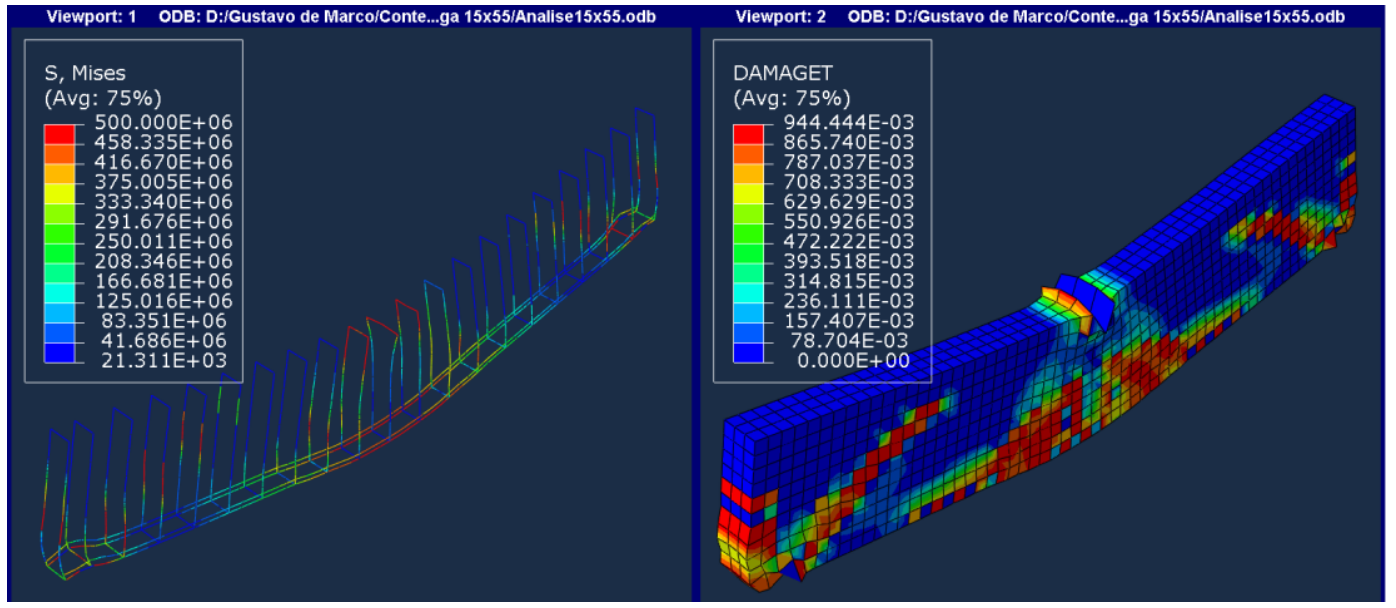

Fonte: Os Autores (2021)

Figura 22 - Evolução da tensão de von Mises e do dano à tração no modelo 6 (3/3)

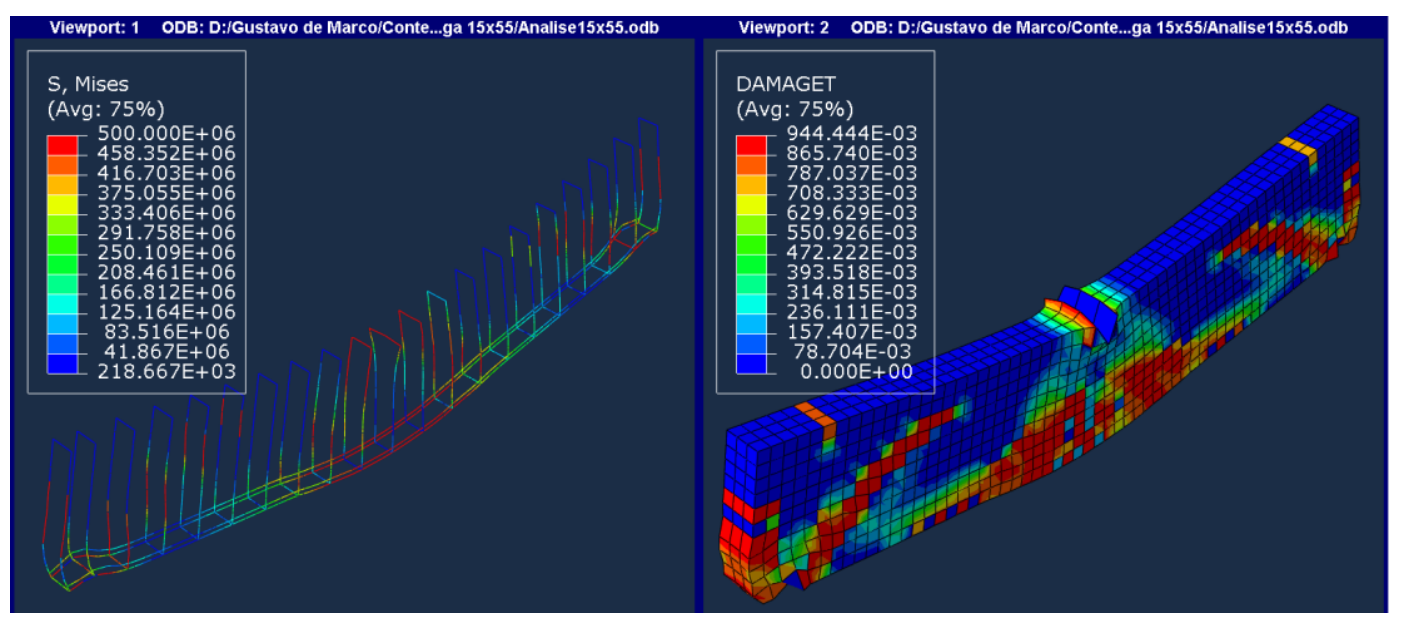

Fonte: Os Autores (2021) 
Figura 23 - Evolução da tensão de von Mises e do dano à tração no modelo 7 (1/3)

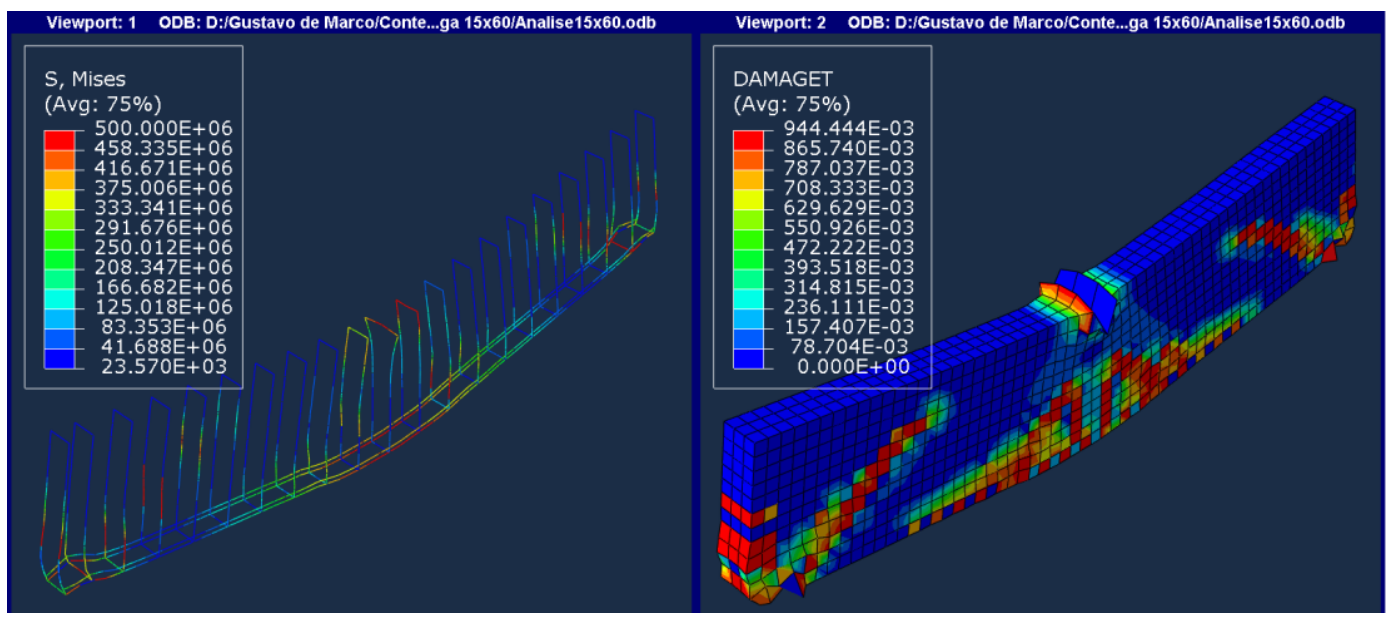

Fonte: Os Autores (2021)

Figura 24 - Evolução da tensão de von Mises e do dano à tração no modelo 7 (2/3)

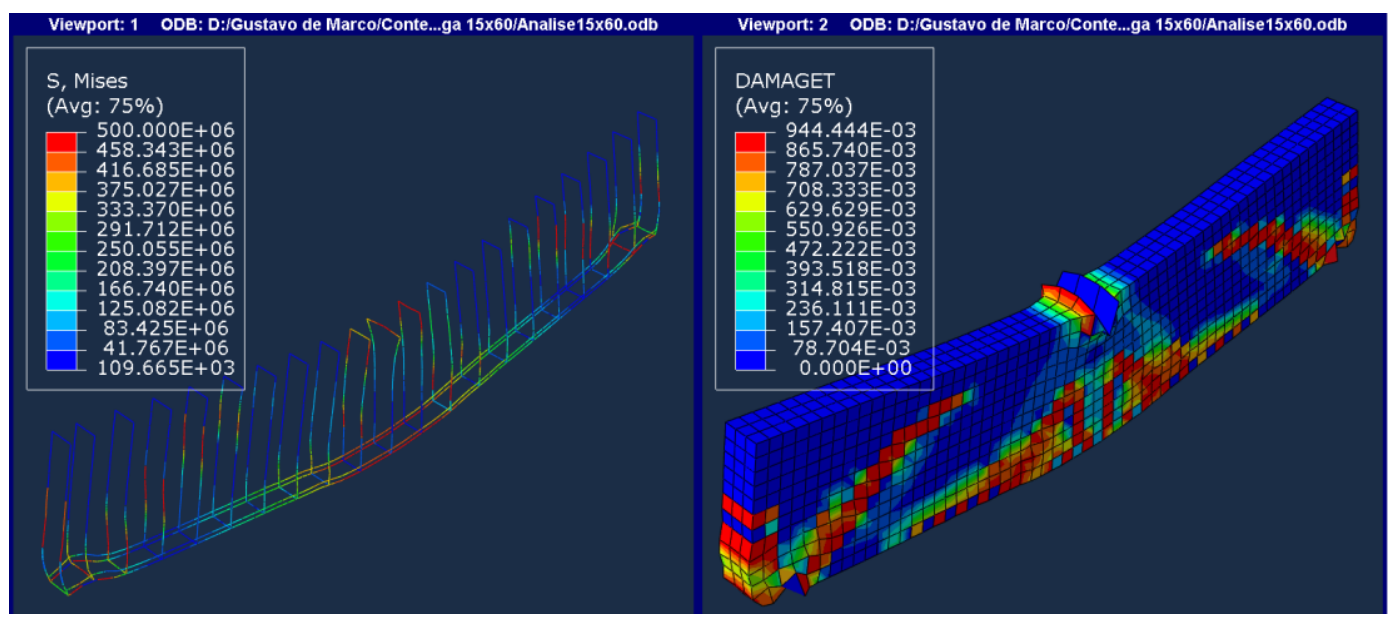

Fonte: Os Autores (2021)

Figura 25 - Evolução da tensão de von Mises e do dano à tração no modelo 7 (3/3)

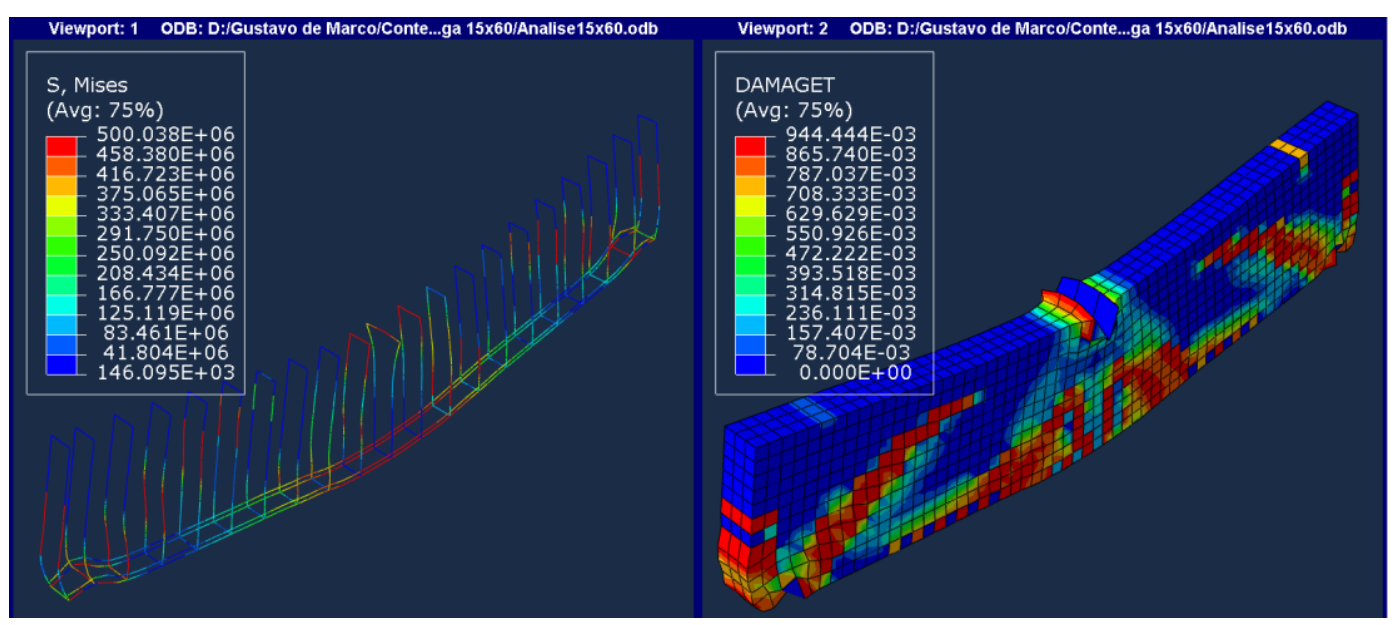

Fonte: Os Autores (2021) 


\section{Análise comparativa dos dois modelos}

De posse dos resultados oriundos dos modelos analítico e numérico, foi elaborada a Tabela 5, comparando as análises individuais de cada modelo.

Tabela 5 -Avaliação comparativa do modo de falha pelos métodos abordados

\begin{tabular}{ccc}
\hline $\begin{array}{c}\text { Modelo } \\
\text { de viga }\end{array}$ & $\begin{array}{c}\text { Modo de falha pelo } \\
\text { modelo analítico }\end{array}$ & $\begin{array}{c}\text { Modo de falha pelo } \\
\text { modelo numérico }\end{array}$ \\
\hline 1 & Flexão & Flexão \\
2 & Flexão & Flexão \\
3 & Flexão & Flexão \\
4 & Flexão & Flexão \\
5 & Cisalhamento & Cisalhamento \\
6 & Cisalhamento & Cisalhamento \\
7 & Cisalhamento & Cisalhamento \\
\hline
\end{tabular}

Fonte: Os Autores (2021)

Sob o viés qualitativo, a Tabela 5 demonstra que o modelo numérico pôde prever os mesmos modos de falha quando comparado ao modelo analítico. Não obstante, compete salientar que a transição entre os modos de falha, ou seja, o momento em que a ruína nas vigas deixa de ser por flexão e passa a ser por cisalhamento, ocorreu em modelos diferentes para cada método de análise. No método analítico observou-se que a transição dos modos de falha ocorreu nos modelos de viga 3 e 4, enquanto que no método numérico, ocorreu no modelo 5.

\section{CONCLUSÕES}

Em virtude da dificuldade de se obter a resposta de um método analítico visando a aproximação de um modelo real, devido à sua complexidade de resolução, optou-se pela simplificação deste modelo realizando uma comparação através das soluções por elementos finitos, que passaram a viabilizar o cálculo e análise de situações mais complexas pela discretização da viga. Os programas computacionais desenvolvidos para a resolução de problemas de engenharia, a exemplo do Abaqus, empregado neste estudo, utilizam o método de elementos finitos para a formulação e resolução de equações a partir da interface de criação e simulação de modelos gráficos.

Com base nos dois métodos supracitados, este estudo investigou os efeitos do carregamento no modo de falha de vigas de concreto armado. Para isso, foram definidos sete modelos com o intuito de caracterizar a ruptura desses elementos lineares com 
variação da altura da seção transversal e a área de armadura longitudinal. Com as equações de equilíbrio, foi desenvolvida a equação para encontrar a força máxima no meio do vão, responsável pela ruptura à flexão. Com o modelo I de cálculo de dimensionamento ao cisalhamento da ABNT NBR 6118 (2014), foi encontrada a relação para o esforço máximo de cisalhamento. Com isso, para os sete modelos, foi calculado os esforços máximos e a partir da comparação entre eles, avaliou-se o modo de falha pelo valor menor obtido entre as duas equações.

Após os cálculos analíticos, os sete modelos de viga foram simulados com elementos finitos no Abaqus, considerando análise física não linear, assim obtendo o resultado gráfico. Com isso, o principal objetivo perscrutado ao longo do trabalho foi atendido. A precisão do modelo analítico foi comprovada pelos resultados do modelo numérico. Ambos os métodos convergiram, com os quatro primeiros modelos rompendo por flexão e os três últimos por cisalhamento. A diferença do momento de transição entre os modos de falha por flexão e cisalhamento pode ser explicada através da quantidade de parâmetros considerados para cada método. O modelo numérico, neste caso, é mais preciso em sua análise e processamento dos dados inseridos, pois considerou elementos tridimensionais e a não linearidade física dos materiais.

A partir dos dados numéricos obtidos pelo modelo analítico, constatou-se também que o aumento proporcional da altura da viga e da área de armadura longitudinal fez com que a resistência à flexão aumentasse a uma taxa de variação maior que a resistência à força cortante. Para esta última manteve-se a armadura transversal constante, variando apenas a parcela resistente do concreto.

A análise estrutural promovida neste trabalho, tanto para o método analítico, como para o numérico, não levou em consideração o peso próprio da viga. Sugere-se, para estudos futuros, a consideração do carregamento distribuído da viga para o método analítico e a consideração da densidade dos materiais para o modelo numérico, bem como a análise e comparação dos resultados e sua significância em relação a este trabalho.

Isso posto, de modo geral, o modelo numérico de elementos finitos atendeu à finalidade de validar o modelo analítico e se mostra como uma ferramenta eficiente para estudos de caso complexos, onde os cálculos analíticos se mostram trabalhosos e dispendiosos. Ademais, a viabilidade da análise, a depender do modelo complexo, fica condicionada ao desempenho de processamento, acarretando eventualmente em alto custo computacional. 
É notório observar que o método analítico, embora simplificado para este caso, não apresentou resultados discrepantes do modelo numérico, sendo permitido pela ABNT NBR 6118 (2014).

\section{REFERÊNCIAS}

ABAQUS. Online Documentation, Version 6.14, Dassault Sistèmes. France, 2014.

AMERICAN CONCRETE INSTITUTE. Building Code Requirements for Structural Concrete (ACI 318-19) and Commentary (ACI 318R-19). Detroit, 2019.

ASSOCIAÇÃO BRASILEIRA DE NORMAS TÉCNICAS. ABNT NBR 6118: Projeto de estruturas de concreto - Procedimento. 3 ed. Rio de Janeiro, 2014.

BATHE, Klaus-Jürgen. Finite Element Procedures. 2. ed. Watertown: Klaus-Jürgen Bathe, 2006.

CARREIRA, Domingo J.; CHU, Kuang-Han. Stress-Strain Relationship for Plain Concrete in Compression. American Concrete Institute Journal, v. 82, n. 6, p. 797804, 1 nov. 1985.

CARREIRA, Domingo J.; CHU, Kuang-Han. Stress-Strain Relationship for Reinforced Concrete in Tension. American Concrete Institute Journal, v. 83, n. 1, p. 21-28, 1 jan. 1986.

CARVALHO, Roberto Chust; FIGUEIREDO FILHO, Jasson Rodrigues de. Cálculo e Detalhamento de Estruturas Usuais de Concreto Armado: Segundo a NBR 6118:2014. 4. ed. São Carlos: EdUFSCar, 2014.

COMITÉ EURO-INTERNATIONAL DU BÉTON. CEB-FIP Model Code 1990. Published by Thomas Telford, London, 1993.

COMITÉ EUROPÉEN DE NORMALISATION. Eurocode 2: Design of Concrete Structures - Part 1-1: General rules and rules for buildings. Ref. No. EM 1992-11:2004+A1:2014 (E). 2014.

DHONDT, Guido. CalculiX CrunchiX USER'S MANUAL, version 2.7.

Massachusetts Institute of Technology, 2014.

FÉDÉRATION INTERNATIONALE DU BÉTON. FIB Bulletin 10: Bond of reinforcement in concrete, State-of-art report, Bulletin No. 10. Ed. by FIB Task Group Bond Models, Convener Ralejs Tepfers, 427 p, 2000.

Recebido em: 01/12/2021

Aprovado em: 23/12/2021

Publicado em: 29/12/2021 